\title{
Resting Brain Activity Varies with Dream Recall Frequency Between Subjects
}

\author{
Jean-Baptiste Eichenlaub ${ }^{1,2}$, Alain Nicolas ${ }^{3}$, Jérôme Daltrozzo ${ }^{1,2}$, Jérôme Redouté ${ }^{4}$, Nicolas Costes ${ }^{4}$ and \\ Perrine Ruby*,1,2 \\ ' CRNL_Lyon Neuroscience Research Center, INSERM UI 028, CNRS UMR 5292, Brain Dynamics and Cognition Team, Centre Hospitalier Le \\ Vinatier (Bât. 452), Lyon, France; ' University Claude Bernard Lyon I, Lyon, France; ${ }^{3}$ Unité d'Exploration Hypnologique, Centre Hospitalier Le \\ Vinatier, Lyon, France; ${ }^{4}$ CERMEP-Imagerie du Vivant, Lyon, France
}

\begin{abstract}
Dreaming is still poorly understood. Notably, its cerebral underpinning remains unclear. Neuropsychological studies have shown that lesions in the temporoparietal junction (TPJ) and/or the white matter of the medial prefrontal cortex (MPFC) lead to the global cessation of dream reports, suggesting that these regions of the default mode network have key roles in the dreaming process (forebrain 'dreamon' hypothesis). To test this hypothesis, we measured regional cerebral blood flow (rCBF) using $\left[{ }^{15} \mathrm{O}\right] \mathrm{H}_{2} \mathrm{O}$ positron emission tomography in healthy subjects with high and low dream recall frequencies (DRFs) during wakefulness (rest) and sleep (rapid eye movement (REM) sleep, N2, and N3). Compared with Low recallers ( $0.5 \pm 0.3$ dream recall per week in average), High recallers $(5.2 \pm 1.4)$ showed higher rCBF in the TPJ during REM sleep, N3, and wakefulness, and in the MPFC during REM sleep and wakefulness. We demonstrate that the resting states of High recallers and Low recallers differ during sleep and wakefulness. It coheres with previous ERP results and confirms that a high/low DRF is associated with a specific functional organization of the brain. These results support the forebrain 'dream-on' hypothesis and suggest that TPJ and MPFC are not only involved in dream recall during wakefulness but also have a role in dreaming during sleep (production and/or encoding). Increased activity in the TPJ and MPFC might promote the mental imagery and/or memory encoding of dreams. Notably, increased activity in TPJ might facilitate attention orienting toward external stimuli and promote intrasleep wakefulness, facilitating the encoding of the dreams in memory.

Neuropsychopharmacology (2014) 39, 1594-1602; doi: I0.1038/npp.20 I4.6; published online 19 February 2014
\end{abstract}

Keywords: sleep; dreaming; default mode network; positron emission tomography; resting state; self

\section{INTRODUCTION}

Despite recent advances (Wamsley et al, 2010; Dresler et al, 2011; Marzano et al, 2011; Eichenlaub et al, 2013), the cerebral correlates of dreaming remain unclear (Maquet and Ruby, 2004; for reviews, see Hobson, 2005; Nir and Tononi, 2010; Ruby, 2011). Since the 1950s, scientists have argued that rapid eye movement (REM) sleep is the neurophysiological state underlying dreaming (Aserinsky and Kleitman, 1953; Dement and Kleitman, 1957; Dement and Wolpert, 1958; Sastre and Jouvet, 1979). On the basis of this hypothesis, scientists have investigated the regional cerebral blood flow $(\mathrm{rCBF})$ during REM sleep to uncover the cerebral correlates of dreaming (eg, Maquet et al, 1996; Braun et al, 1998).

However, the REM sleep hypothesis of dreaming has been challenged (Solms, 2000). First, 10-20\% of awakenings from

*Correspondence: Dr P Ruby, CRNL-Lyon Neuroscience Research Center, INSERM UI028, CNRS UMR 5292, Brain Dynamics and Cognition Team, Centre Hospitalier Le Vinatier (Bât. 452), 95, Boulevard Pinel, Bron CEDEX 69675, France, Tel: +33 (0)4 721389 21, E-mail: perrine.ruby@inserm.fr

Received 28 February 20 I3; revised 8 January 2014; accepted 9 January 2014; accepted article preview online 16 January 2014
REM sleep are not followed by a dream report, and a substantial proportion of awakenings from non-REM (NREM) sleep are followed by a dream report (mean $50 \%$, range $0-75 \%$; for a review, see Nielsen, 2000). These results show that REM sleep is not a necessary condition for dream report to occur. Secondly, studies have shown that lesions in the temporoparietal junction (TPJ) and the white matter of the medial prefrontal cortex (MPFC) were associated with a cessation of dream reporting, with no REM sleep disturbance (Murri et al, 1985; Solms, 1997; Bischof and Bassetti, 2004). These results suggest that REM sleep is not sufficient for dream report to occur. On the basis of these findings, Solms (2000) put forward the forebrain 'dream-on' hypothesis, proposing that dreaming and REM sleep are dissociable states, that is, that dreaming may occur in any sleep stage. Solms argued that dreaming is controlled through forebrain mechanisms involving at least TPJ and MPFC.

To test this hypothesis, we compared the brain activity $\left(\left[{ }^{15} \mathrm{O}^{\mathrm{H}} \mathrm{H}_{2} \mathrm{O}\right.\right.$ positron emission tomography (PET)) of healthy subjects with high and low dream recall frequencies (DRFs) (Goodenough et al, 1959; Lewis et al, 1966; Eichenlaub et al, 2013) during both wakefulness (rest) and sleep. To ensure that a great proportion of the subjects would sleep during 
the experiment, the subjects were sleep deprived the night before, and the data acquisition was scheduled in the afternoon, that is, after $30 \mathrm{~h}$ of wakefulness. Midafternoon corresponds to the peak of daytime sleepiness in humans (Lavie, 1986). A 2-h midafternoon nap after $30 \mathrm{~h}$ of sleep deprivation result in a shortened sleep latency, reduced wake time after sleep onset, increased percentage of slow wave sleep (N3), reduced percentage of REM sleep, and shortened REM sleep latency (Benoit and Foret, 1992; Vgontzas et al, 2007). This paradigm maximized the chance that the subjects would sleep in the scanner for a sufficient amount of time to acquire scans in all sleep stages. Moreover, the subjects underwent a neuropsychological assessment on the night of sleep deprivation to detect the potential cognitive or personality differences between the High (HR) and Low recaller (LR) groups (Figure 1).

\section{MATERIALS AND METHODS}

\section{Subjects}

The subjects were informed of the study through an announcement. The announcement briefly described the sleep study, and the subjects were unaware that DRF was the main criterion for inclusion in the study. To apply for the study, the subjects filled out a questionnaire (adapted from Goodenough et al, 1959 and Schredl, 2002, 2004) concerning sleep and dream habits. On the basis of their answers, the subjects with high and low DRF (DRF superior to three dream recalls per week and inferior to two dream recalls per month, respectively) were selected for further consideration. The preselected subjects were interviewed on the phone. The experimenter defined a dream as being 'either a long and bizarre story, an image that vanishes rapidly, or a feeling of having dreamt.' Then, the following question was asked: 'Usually, how many mornings in the week do you wake up with a dream in mind?' Subjects who confirmed that they recalled dreams more often than 3 mornings in a week were selected as HRs, and those who confirmed that they recalled dreams less often than 1.25 mornings in a week were selected as LRs. In addition, we ensured that the subjects of the two groups did not differ in age, usual sleep duration (USD), and body mass index (BMI). A total of 41 healthy male volunteers were recruited (Supplementary Table S1), 21 HRs $(\mathrm{DRF}=5.2 \pm 1.4$ dream reports per week; age $=23.7 \pm 4.8$ years old; $U S D=7.5 \pm 1 \mathrm{~h} ; \mathrm{BMI}=23.3 \pm 2.1 \mathrm{~kg} / \mathrm{m}^{2}$ ) and 20 LRs $(\mathrm{DRF}=0.5 \pm 0.3$ dream reports per week; age $=22.1 \pm 2$ years old; $U S D=7.4 \pm 1 \mathrm{~h}$; $B M I=23.6 \pm 3.8 \mathrm{~kg} / \mathrm{m}^{2}$ ). No subjects had a history of medical, neurological, or psychiatric disease and no individual was currently on medication. The subjects provided written informed consent according to the Declaration of Helsinki. The study was approved by the local ethics committee (CCPPRB, Centre Léon Bérard, Lyon, France), and the subjects were paid for participation.

\section{Behavioral Tests}

The night before the experiment, the subjects underwent total sleep deprivation. In the evening (between 2200 hours and midnight), the subjects were presented with various tests to assess the potential between group differences at the cognitive and personality levels (Schredl et al, 2003). We used an implicit visual memory test (Cory and Ormiston, 1975), the Embedded Figures Test (Witkin, 1950), a depression scale (Pichot et al, 1984a, b), the Mindful Attention Awareness Scale (Brown and Ryan, 2003), the Attachment Styles Scale (Simpson, 1990; Bouthillier et al, 1996), the Social Curiosity Scale (Renner, 2006), and the Bortner Questionnaire (Bortner, 1969; Johnston and Shaper, 1983) to assess high-strung vs easy-going personalities. See Supplementary Data for a description of the behavioral tests.

\section{Paradigm and Scanning Procedure}

The experimental design is presented in Figure 1. The subjects were scanned during sleep (N2, N3, and REM sleep were targeted) and post-sleep resting wakefulness. To increase the probability for sleep in the scanner, the subjects were deprived of sleep and scanned in the following afternoon. The subjects were asked to arrive in the sleep laboratory of the psychiatric hospital (Hopital du Vinatier,
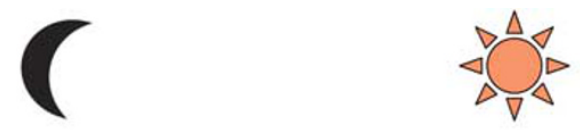

Night Morning Afternoon

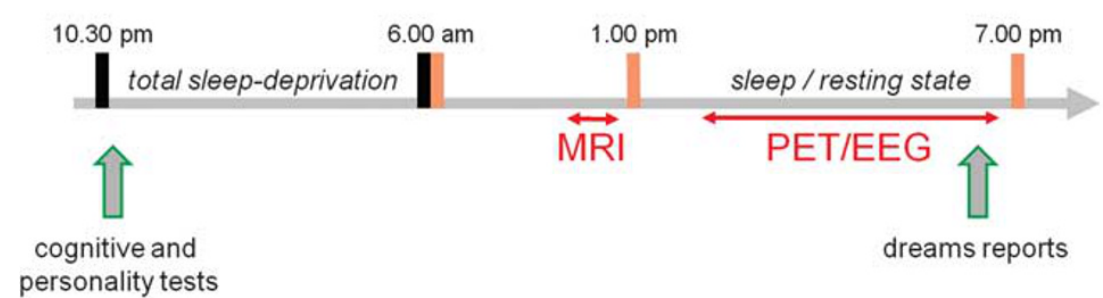

Figure I Experimental design. The subjects were sleep deprived the night before the positron emission tomography (PET) acquisition. In the evening, the subjects underwent a neuropsychological assessment. In the morning, an anatomical magnetic resonance imaging (MRI) was acquired. In the afternoon, the subjects were polysomnographically monitored in the PET scan during resting. The scans were acquired during resting in different sleep stages (N2, N3, and rapid eye movement (REM) sleep) and during post-sleep wakefulness. At the end of the experiment, the subjects (High recallers and Low recallers) were asked to recall their dreams. 
Lyon, France) at 2230 hours the night before the experiment. The participants were maintained in an illuminated room (white neon light) with magazines, puzzles, DVDs, a laptop, and snacks (salted and soft biscuit, olives, water, and fruit juice). They were instructed not to sleep at any point through the entire night and to maintain as little physical activity as possible. Energy drinks were prohibited. The nurses kept an eye on the subjects throughout the night. The monitoring of body movements through wrist actigraphy (Cambridge Neuroscience, Cambridge, UK) enabled the experimenters to check in the morning that the subject did not fall asleep during the night. In the morning, the subjects were offered breakfast and a shower. They were then transferred to the neuroimaging center (CERMEP) to undergo a structural MRI (a T1-weighted three-dimensional MP-RAGE sequence acquired with a $1.5 \mathrm{~T}$ scanner; Siemens, Allegra, Erlangen, Germany). At approximately noon, the subjects were provided a simple meal (sandwich and desert). The PET session was initiated at 1300 hours, with the placing of electrodes for the recording of electroencephalogram (EEG), electromyogram (EMG), and electrooculogram (EOG). For the EEG recordings, four scalp electrodes were manually positioned according to the extended International 10-20 System (C3, C4, Cz, and $\mathrm{Oz}$ ). The reference electrode was placed on the tip of the nose, and the ground electrode was placed on the forehead. The EOG was recorded from two electrodes placed on the supraorbital ridge of the left eye and the infraorbital ridge of the right eye. For the EMG, two electrodes were attached to the chin. The subjects were then installed in the PET scanner, and a venous catheter to administer the tracer was placed in an antecubital fossa vein of the left forearm. Head movements were minimized using a vacuum cushion. When the installation was finished, the light was switched off and the subject was given permission to sleep. A Neuroscan Compumedics system with Synamps DC-coupled amplifiers was used to amplify and visualize the EEG, EMG, and EOG signals. Online scoring of the polysomnographic data according to the standardized criteria (Rechtschaffen and Kales, 1968; Silber et al, 2007) was used to determine when to acquire the scans. We intended to acquire three PET rCBF scans per vigilance state of interest, that is, N2, N3, REM sleep, and post-sleep wakefulness. A Siemens CTI HR $+(63$ slices, $15.2 \mathrm{~cm}$ axial field of view) tomograph with collimating septa retracted operating in the three-dimensional mode was used for PET acquisitions. Before scan acquisition, the measure for attenuation correction was performed using a 10 -min ${ }^{68} \mathrm{Ge}$ transmission scan. When the experimenters considered that the vigilance state of the subject was stable, an intravenous bolus injection programmed to be of $333 \mathrm{MBq}\left[{ }^{15} \mathrm{O}\right] \mathrm{H}_{2} \mathrm{O}$ was administered by an automated water production device (ARMC Melbourne; TochonDanguy et al, 1995). The dose was counted online by a Geiger-Müller counter and pushed in the arm vein by a pump. The scans were initiated when the brain radioactive count rate reached a threshold value $(400 \%$ of a 40 s prescan background noise measurement). The brain $\left[{ }^{15} \mathrm{O}\right] \mathrm{H}_{2} \mathrm{O}$ activity was counted for $60 \mathrm{~s}$. The 60 -s mean activity image was reconstructed with attenuation, scatter, and random correction using a three-dimensional-filtered back projection algorithm (Hanning filter cutoff 0.5 pixel per cycle). The reconstructed volumes comprised 63 contiguous 2.42-mm-thick transaxial slices in a $128 \times 128$ matrix of $2.01 \times 2.01 \mathrm{~mm}^{2}$ pixels. The PET emission scans were considered as an index of brain rCBF (Raichle et al, 1983). The PET scans were repeated with a minimal time interval of $10 \mathrm{~min}$. Upon waking, the subjects were asked to report whether they had dreamt during their sleep in the scanner. If the answer was positive, the subjects were asked to fill out a questionnaire concerning the content of their dream.

\section{Data Analysis}

No anomalies were detected in the structural MRI. The PET images were analyzed voxel by voxel using Statistical Parametric Mapping (SPM8 software; Wellcome Department of Cognitive Neurology, London, UK) implemented in MATLAB (MathWorks, Natick, MA). For each subject, the images were realigned to the first scan to correct for head movements (rigid body registration with 6 degrees of freedom, 3 degrees for translation, and 3 degrees for rotation, implemented in the SPM8 software) and normalized into the MNI stereotaxic space using the $\left[{ }^{15} \mathrm{O}\right] \mathrm{H}_{2} \mathrm{O}$ PET template provided in SPM8. The data were smoothed using a Gaussian filter with a full-width half-maximum (FWHM) parameter set to $8 \mathrm{~mm}$ (Friston et al, 1995). Each individual scans were masked out for voxels below $80 \%$ of the global mean of the scan. Voxel-based analysis was performed on the intersection of the individual masks. The statistical analysis included one fixed-effect analysis to assess condition effects (conditions: wakefulness, N2, N3, and REM) and four random-effect analyses to assess group differences (HR $v s$ LR) in the different vigilance states (wakefulness, N2, N3, and REM). For the fixed-effect analysis, the analysis of variance included the condition, subject, and group effects and the intracerebral global mean, which was covaried out (flexible factorial design; total number of scans, 366: $73 \mathrm{~N} 2$ scans, $111 \mathrm{~N} 3$ scans, 44 REM sleep scans, and 138 wakefulness resting state scans; one subject was excluded from the analysis owing to large head movements between conditions). Post hoc contrasts were assessed to identify the significant difference between conditions, and were used to create SPM $\{\mathrm{t}\}$ maps. The SPM $\{\mathrm{t}\}$ maps were thresholded at $p<0.05$ (corrected for multiple comparisons using familywise error rate (FWE)), $t>4.82$, and $k>20$ (extent threshold). Three contrasts were considered: REM sleep $v s$ wakefulness, wakefulness vs REM sleep, and REM sleep vs N3. The random-effect statistical analyses comprised four between-group two-sample $t$-tests for the REM sleep (26 scans from HRs vs 20 scans from LRs), the N2 state (34 scans from HRs vs 43 scans from LRs), the N3 state (59 scans from HRs $v s 55$ scans from LRs), and the wakefulness state (79 scans from HRs vs 60 scans from LRs). The global differences in $\mathrm{rCBF}$ were covaried out in these comparisons (the equation used is presented in the Supplementary Data). This design has been used in previous studies to compare brain states between healthy subject and patient groups (Malaspina et al, 2004; Mazza et al, 2006; Coez et al, 2009; Silva et al, 2010). The correction for multiple nonindependence of voxels was performed on the whole brain (FWE, $p=0.05$ ), and an extent threshold of $k>10$ was applied. In addition, the FWE $p$-value threshold was divided by four to correct for multiple comparisons (the four between-group two-sample $t$-tests). 
The anatomical identification was performed using the free Marina software (MAsks for Region of INterest Analysis, developed in the Bender Institute of Neuroimaging, Giessen, Germany; http://www.bion.de/) and the atlas of Duvernoy (1991).

\section{RESULTS}

\section{Behavioral Results}

Thirty-seven subjects succeeded in sleeping in the scanner more than 15 minutes, 19 HRs and 18 LRs. The mean sleep duration in the PET scan was $108 \pm 65 \mathrm{~min}$ for the HRs and $120 \pm 64 \mathrm{~min}$ for the LRs (no significant difference). After awakening in the scanner, fewer LRs reported dreams than did HRs ( $40 \%$ of LRs and $90 \%$ of HRs reported a full or a white dream). Several characteristics of sleep and dreams in the scanner are reported in Supplementary Table S2.

No significant differences were found between HRs and LRs in the tests used to assess memory, visual imagery, and personality traits. See Supplementary Data for more details.

\section{PET Results}

A total of 430 scans were acquired and 376 images were acquired during stable states of vigilance, as detailed in Table 1. Owing to the short half-life of $\left[{ }^{15} \mathrm{O}^{-} \mathrm{H}_{2} \mathrm{O}(123 \mathrm{~s})\right.$, the production method (ARMC Melbourne; Tochon-Danguy et al, 1995), and the uncertainty of the time of the scans, the injected dose varied across subjects $(298 \mathrm{MBq} \pm 81$ in average) but was not significantly different in HRs and LRs (Supplementary Table S3). As HR and LR groups did not differ in BMI (Supplementary Tables S1 and S3), we coherently observed no significant difference between the mean global activity of the HR and LR scans used for group comparisons (Supplementary Table S3).

Effect of the state of vigilance. Contrasts between conditions (Supplementary Figure S1 and Supplementary Tables S4-6) confirmed previous results (Braun et al, 1997, 1998; Maquet et al, 2005) and suggest that rCBF during sleep does not vary much whether sleep happens at night without previous sleep deprivation (Maquet et al, 2005) or during the afternoon after sleep deprivation (Braun et al, 1997, 1998).

Effect of the group (HRs vs LRs). The results of the contrast between HRs and LRs in different vigilance states are presented in Table 2. As the aim of this study was to test

Table I Number of Scans Acquired, Number of Subjects for which Scans could be Acquired (Between Brackets), and Mean Number of Scan per Subject \pm SD (Between Square Brackets) ${ }^{a}$

\begin{tabular}{ccccc}
\hline & Wakefulness & N2 & N3 & REM sleep \\
\hline HR & $79(21)$ & $34(15)$ & $59(17)$ & $26(10)$ \\
& {$[3.8 \pm 1.4]$} & {$[2.3 \pm 1.5]$} & {$[3.5 \pm 0.9]$} & {$[2.6 \pm 1.4]$} \\
LR & $60(18)$ & $43(15)$ & $55(17)$ & $20(8)$ \\
& {$[3.3 \pm 1.6]$} & {$[2.9 \pm 1.5]$} & {$[3.2 \pm 0.8]$} & {$[2.5 \pm 0.9]$} \\
\hline
\end{tabular}

Abbreviations: HR, High recallers; LR, Low recallers.

${ }^{a}$ For HRs and LRs in all conditions (wakefulness, N2, N3, and REM sleep). whether activity in the TPJ and MPFC differed between HRs and LRs, only the results in these brain areas were considered.

We found that $\mathrm{rCBF}$ in the TPJ was higher in HRs than in LRs during REM sleep, N3, and the awake resting state. No rCBF difference in TPJ was observed between the two groups in N2. In MPFC, the rCBF was higher in HRs than in LRs during REM sleep and wakefulness. No rCBF difference in the MPFC was found between the two groups in N2 and N3 (Table 2 and Figures 2 and 3, the $\beta$ parameters of the general linear model are presented in the Supplementary Data).

\section{DISCUSSION}

This study reports, for the first time, functional neuroanatomical correlates of DRF in healthy subjects. Compared with LRs, HRs showed higher rCBF in the TPJ during REM sleep, N3, and wakefulness, and in the MPFC during REM sleep and wakefulness. No behavioral differences were observed between the two groups, that is, in implicit visual memory, visual imagery, and personality traits (mindful attention awareness, depression, attachment style, social curiosity, and type A/B personality scales).

\section{From the REM Sleep Hypothesis of Dreaming to the Forebrain Hypothesis of Dreaming}

At the end of the 1950s, scientists argued that REM sleep was the neurophysiological state underlying dreaming

Table 2 Brain Areas More Activated in High Recallers than in Low Recallers

\begin{tabular}{|c|c|c|c|c|c|c|}
\hline \multirow[t]{2}{*}{ Brain region } & \multirow[t]{2}{*}{$\mathbf{H}$} & \multicolumn{3}{|c|}{ Coordinates } & \multirow[t]{2}{*}{ t-Value } & \multirow{2}{*}{$\begin{array}{l}p-V a l u e \\
\text { corrected }\end{array}$} \\
\hline & & $\mathbf{x}$ & $\mathbf{y}$ & $\mathbf{z}$ & & \\
\hline \multicolumn{7}{|l|}{ Wakefulness } \\
\hline Inferior frontal gyrus & $\mathrm{R}$ & 39 & 5 & 34 & 6.68 & 0.000 \\
\hline Superior frontal gyrus & $\mathrm{R}$ & 20 & 33 & 36 & 5.81 & 0.001 \\
\hline Middle frontal gyrus & $\mathrm{R}$ & 38 & 9 & 49 & 5.32 & 0.010 \\
\hline Angular gyrus & $L$ & -48 & -54 & 28 & 5.60 & 0.003 \\
\hline \multirow[t]{2}{*}{ Middle temporal gyrus } & $\mathrm{R}$ & 45 & -67 & 10 & 5.35 & 0.009 \\
\hline & $\mathrm{L}$ & -66 & -37 & -15 & 5.59 & 0.003 \\
\hline \multirow[t]{2}{*}{ Fusiform gyrus } & $L$ & -40 & -67 & -12 & 5.48 & 0.005 \\
\hline & $L$ & -33 & -7 & -35 & 5.47 & 0.005 \\
\hline \multicolumn{7}{|l|}{ REM sleep } \\
\hline Medial prefrontal cortex & $\mathrm{R}$ & 20 & 42 & 4 & 6.43 & 0.003 \\
\hline Angular gyrus & $L$ & -45 & -54 & 28 & 6.21 & 0.006 \\
\hline Middle occipital gyrus & $L$ & -32 & -67 & 31 & 6.06 & 0.010 \\
\hline \multicolumn{7}{|l|}{ N2 } \\
\hline $\begin{array}{l}\text { Medial and inferior surfaces } \\
\text { of the occipital lobe }\end{array}$ & $\mathrm{R}$ & 26 & -58 & 12 & 6.79 & 0.000 \\
\hline \multicolumn{7}{|l|}{ N3 } \\
\hline Supramarginal gyrus & $\mathrm{R}$ & 63 & -43 & 34 & 5.37 & 0.012 \\
\hline
\end{tabular}

Abbreviations: $H$, hemisphere; $L$, left; $R$, right; $x, y, z, M N I$ coordinates. $p<0.05$ corrected using FWE rate, $t>4.89$ (wakefulness), $t>5.47$ (REM sleep), $t>5.07$ (N2), and $t>4.99$ (N3). Extent threshold, $k>10$ voxels. 


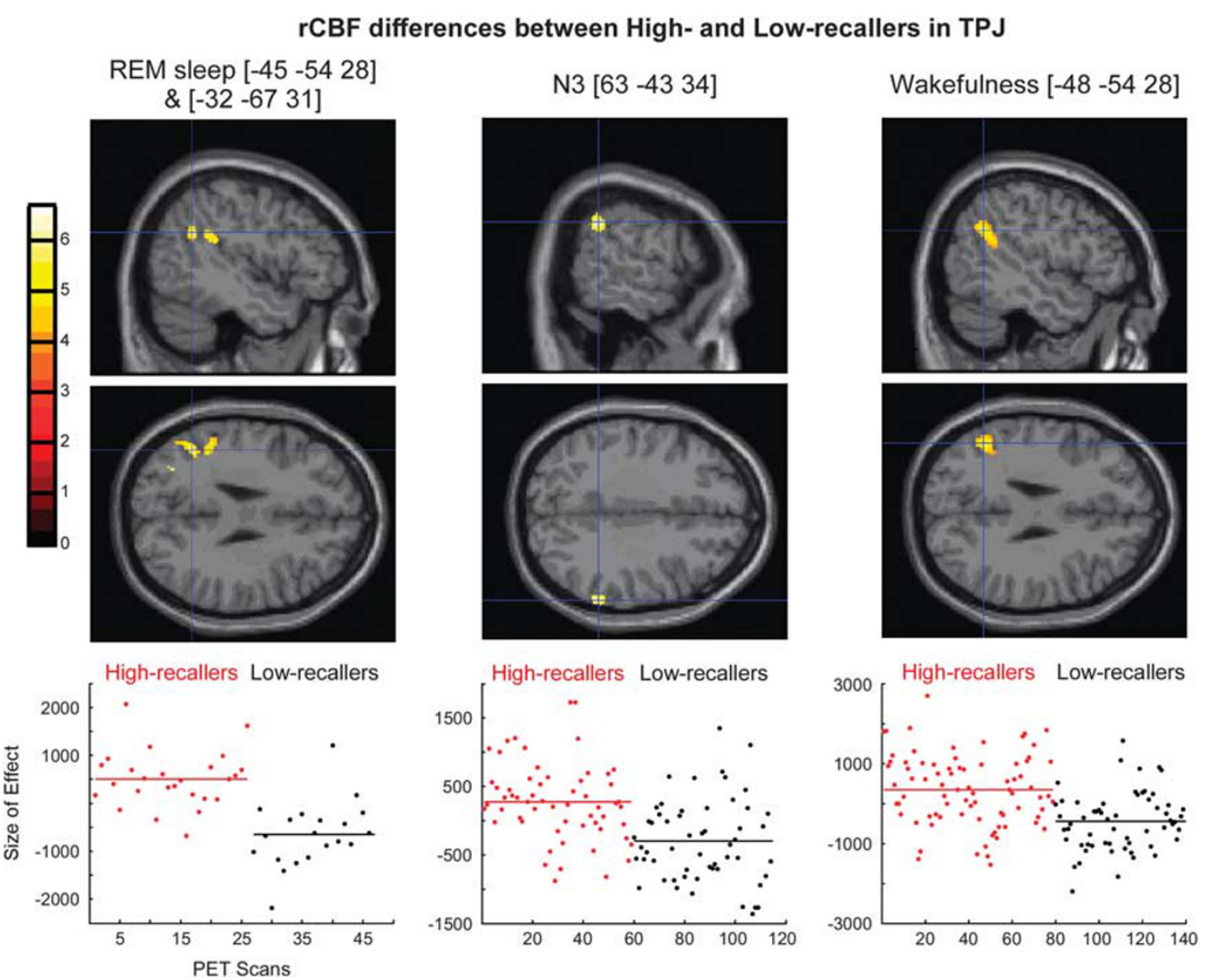

Figure 2 Regional cerebral blood flow (rCBF) differences in temporoparietal junction (TPJ) between High recallers and Low recallers during rapid eye movement (REM) sleep, N3, and wakefulness. Upper panel: Sagittal and axial sections of the brain showing foci with higher activation in High recallers than in Low recallers during REM sleep [ $-45-54$ 28] and [ $-32-673$ I], N3 [63 - 43 34], and wakefulness [ -48 - 54 28]. Foci of activation have been superimposed onto the normalized single-subject magnetic resonance imaging (MRI) provided with SPM8 at a threshold of $p<0.00 \mathrm{I}$ uncorrected. Lower panel: Plots of the fitted response in the peak voxel for the contrast High recallers vs Low recallers in each condition. Each circle represents one scan. Red circles, scans acquired in High recallers, and black circles, scans acquired in Low recallers. MNI (Montreal Neurological Institute) coordinates are presented between brackets.

(Aserinsky and Kleitman, 1953; Dement and Kleitman, 1957; Dement and Wolpert, 1958; Sastre and Jouvet, 1979). Indeed, 'the discovery of the brainstem mechanisms that control REM sleep (Jouvet, 1962; McCarley and Hobson, 1975) has led to the further inference that the same mechanisms control dreaming' (Solms, 2000, p 843). However, the REM sleep hypothesis of dreaming has been challenged, and Solms (2000) argued that dreaming and REM sleep are dissociable states. According to the Solms' forebrain 'dream-on' hypothesis, dreaming can occur in all sleep stages and is controlled through forebrain mechanisms involving, at least, the TPJ and MPFC. In the present study, we tested this hypothesis in healthy subjects and showed that HRs had higher rCBF in TPJ and MPFC than LRs during both sleep (including NREM sleep) and wakefulness. These results are consistent with those of our previous study (Eichenlaub et al, 2013) showing ERP differences between HRs and LRs in all vigilance states and neuropsychological findings showing that lesions in the TPJ and the white matter of the MPFC lead to a total cessation of dream reporting (Solms, 1997). Taken together, these results support the forebrain 'dream-on' hypothesis (Solms, 2000) and suggest that TPJ and MPFC have a key role not only in dream recall during wakefulness but also in the dreaming process during sleep.

\section{Resting State Differences between HRs and LRs}

During the resting state, the $\mathrm{rCBF}$ is not homogeneous. The set of brain regions showing the highest blood flow during rest was labeled default-mode network (DMN) (Gusnard and Raichle, 2001; Raichle et al, 2001). The DMN comprises the MPFC, precuneus, TPJ, and temporal poles, and this network is characterized by high activity during the resting state (mind wandering) and reduced activity during goaldirected actions (Gusnard and Raichle, 2001; Raichle et al, 2001; Raichle and Mintun, 2006) and sleep (Baars et al, 2003). The tendency for the mind to wander, as assessed through subjective reports, was positively correlated with activity in the DMN (Mason et al, 2007). In the present study, while subjects were resting in the scanner, the $\mathrm{rCBF}$ was higher in HRs than in LRs in both the TPJ and MPFC during wakefulness. During sleep, the $\mathrm{rCBF}$ was higher in HRs than in LRs in the TPJ during REM sleep and N3, and 
rCBF differences between High- and Low-recallers in MPFC

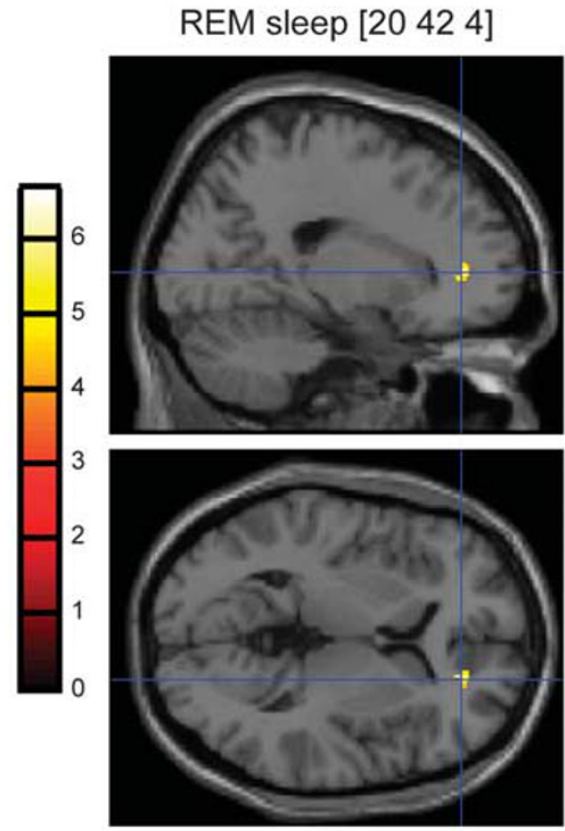

Wakefulness [20 33 36]
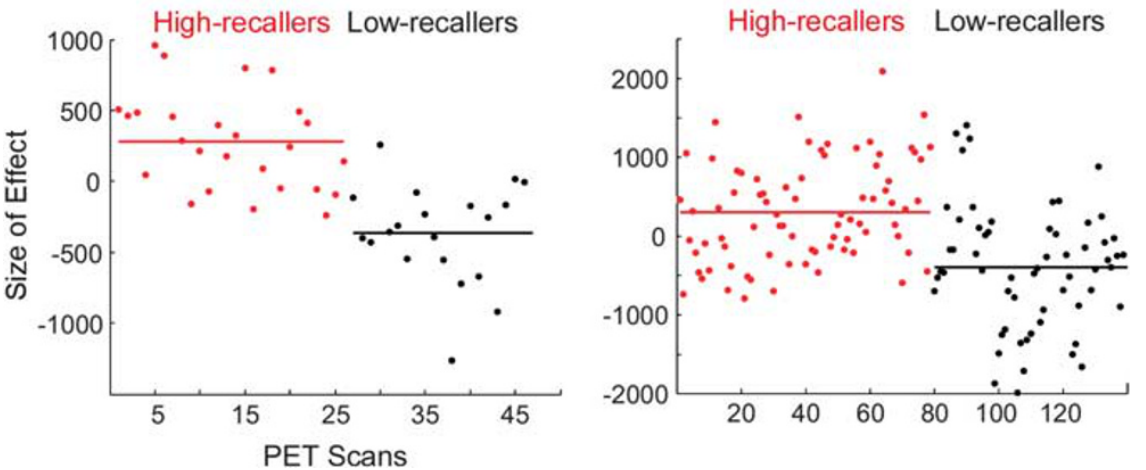

Figure 3 Regional cerebral blood flow (rCBF) differences in the medial prefrontal cortex (MPFC) between High and Low recallers during rapid eye movement (REM), sleep, and wakefulness. Upper panel: Sagittal and axial sections of the brain showing the foci with higher activation in High than in Low recallers during REM sleep [20 42 4] and wakefulness [20 33 36]. The foci of activation have been superimposed onto the single-subject magnetic resonance imaging (MRI) of SPM8 at the threshold of $p<0.00$ I uncorrected. Lower panel. Plots of the fitted response in the peak voxel for the contrast High vs Low recallers in each condition. Each circle represents one scan. Red circles, scans acquired in High recallers, and black circles, scans acquired in Low recallers. MNI (Montreal Neurological Institute) coordinates are presented between brackets.

in the MPFC during REM sleep. Thus, the two groups showed significant differences in two constituents of the DMN during both wakefulness and sleep, suggesting that the neural substrate of dreaming could be a subsystem of the DMN, as suggested previously (Domhoff, 2011).

During wakefulness, the increased activity in the DMN in HRs might be associated with increased wandering of the mind. Conversely, LRs would be less absorbed in their inner world than HRs. More precisely, according to a recent review proposing functional roles for the different brain regions of the DMN (Legrand and Ruby, 2009), these results could suggest that HRs were more involved than LRs in episodic memory recall and evaluative processing.

On the basis of this interpretation of the functional results, one may conclude that HRs were deliberately involved in episodic memory recall during the wakefulness scans, as these subjects tried to remember their dreams. This hypothesis is, however, unlikely because both LRs and
HRs were asked to try to remember the content of their dreams before the wakefulness scans, and all subjects might have tried to remember a dream (and recruit brain regions involved in episodic memory recall and evaluative processes), even if they failed to recall one.

Another possible interpretation is that these results reflect neurophysiological trait differences rather than strategy/task differences between HRs and LRs. Our previous ERP results (Eichenlaub et al, 2013), and the PET results showing that group differences in the DMN persist during sleep, support this hypothesis. Indeed, the group differences during sleep cannot be explained by group differences in explicit cognitive strategies, thus supporting the hypothesis of different functional organization of the brain in HRs and LRs. In other words, HRs and LRs likely have different neurophysiological traits, with the HRs' trait characterized by increased activity in the TPJ and MPFC. This neurophysiological profile would promote dream production and/or memory. 


\section{How Variations in TPJ and MPFC Spontaneous Activity Influence DRF?}

TPJ is involved in numerous cognitive tasks, such as perspective taking (Ruby and Decety, 2001, 2003, 2004), language (Price, 2010), motor control (Peigneux et al, 2004), mental imagery (Kosslyn et al, 2001), episodic memory retrieval (Wagner et al, 2005), and attention orientation (Corbetta et al, 2008; Holeckova et al, 2008; Shulman et al, 2010). MPFC is involved in mind representations and evaluation (Legrand and Ruby, 2009).

It is possible that the relatively smaller decrease in the activity in the TPJ during REM sleep and N3 in HRs facilitates the mental imagery of a dream. In REM sleep, HRs also showed higher rCBF than LRs in the MPFC. Several studies have shown that activity in the MPFC is higher in REM sleep than in N3 (Braun et al, 1997; Maquet et al, 2000), and similar during wakefulness and REM sleep (Maquet et al, 2005). During REM sleep, the relatively increased activity of this region, involved in the attribution of thoughts to characters, might facilitate the social and story-like attributes of REM dreams (eg, more characters appear in REM dreams compared with NREM dreams; Foulkes, 1962; Lewis et al, 1966; Hobson et al, 2000) in HRs. An increase of the social dimension of the dream might make it interesting,' which could facilitate its encoding in memory.

In an alternative hypothesis, TPJ's role in attentional processes may also participate in the DRF difference between HRs and LRs. The TPJ is coactivated with the dorsal network during stimulus-driven shifts of spatial attention, and TPJ activation is not restricted to stimulus-driven shifts of spatial attention, but rather occurs for a broad range of stimulusdriven transitions (Corbetta et al, 2008; Shulman et al, 2010). Hence, from this perspective, owing to increased spontaneous activity in the TPJ, HRs might be more reactive to the environment than LRs during both wakefulness and sleep. We showed that it is indeed the case owing to an eventrelated potential study comparing the brain reactivity to first names presented rarely and randomly among pure tones in HRs and LRs. In response to first names, the attentionorienting brain response, known to recruit TPJ (Knight et al, 1989; Opitz et al, 1999; Holeckova et al, 2008), was larger in HRs than in LRs during wakefulness, and the amplitude of this response was correlated to the total duration of intrasleep wakefulness. The greater brain reactivity (larger amplitude of the brain responses) in HRs $v s$ LRs may explain that HRs show an increased duration of intrasleep wakefulness as compared with LRs (Eichenlaub et al, 2013; see also Ruby et al, 2013). The increase in intrasleep wakefulness in HRs could then explain their high DRF. Indeed, according to the hypothesis of Koulack and Goodenough (1976), nocturnal awakenings facilitate the encoding of the dream in the memory, thereby facilitating the recall of dreaming upon awakening in the morning. One novelty of our results is to provide a possible explanation for why HRs present more and longer intrasleep wakefulness than LRs: an increased brain reactivity to stimuli in the environment through increased spontaneous activity in TPJ.

Future studies are needed to determine to what extent HRs and LRs differ in attentional abilities, using attentional blink (Raymond et al, 1992) and attention-orienting tasks (Holeckova et al, 2006, 2008; Eichenlaub et al, 2012).

\section{Potential Confounding Factors}

Between-group behavioral and personality differences. rCBF differences observed between HRs and LRs in our study cannot be explained through obvious or large cognitive differences between the two groups. Consistent with previous studies, showing no clear cognitive difference between HRs and LRs (Blagrove and Pace-Schott, 2010; Ruby, 2011), we observed no differences between the two groups in the tasks and scales assessed in our study (ability tested: implicit visual memory, embedded figure perception, verbal fluency, and mindful attention awareness; personality traits/style assessed: depression, attachment style, social curiosity, and type A/B).

Sleep deprivation. Given that sleep deprivation modifies recovery sleep parameters (see Introduction), our paradigm could have biased the results concerning the cerebral correlates of DRF. However, the following arguments argue against this hypothesis. First, sleep deprivation was applied to both HRs and LRs, as a consequence the specific effect of sleep deprivation should be cancelled in any comparison between the two groups. In addition, to our knowledge, no studies have provided arguments, suggesting an interaction effect between sleep deprivation and DRF. Coherently, no discrepancy in recovery sleep duration was observed between the two groups (Supplementary Table S2). Second, in our study, the results of the sleep stage effect (Supplementary Figure S1) match quite well with previous results (Braun et al, 1997, 1998; Maquet et al, 2005), which suggests that $\mathrm{rCBF}$ during sleep is not very different whether sleep occurs at night without previous sleep deprivation or during the afternoon after sleep deprivation.

\section{CONCLUSION}

Our study demonstrates that differences in DRF are associated with differences in spontaneous brain activity in the TPJ and MPFC during both sleep and wakefulness. These results show that HRs and LRs have different functional organization of the brain during the resting state and thus different neurophysiological traits. The neurophysiological trait of HRs might facilitate dream production and/or dream memory. Notably, increased activity in the TPJ might facilitate attention orienting toward external stimuli and promote intrasleep wakefulness, thereby facilitating the encoding of the dreams in memory. In general, these results suggest that the spontaneous brain activity is closely associated with the psychological characteristics of the subject.

\section{FUNDING AND DISCLOSURE}

This work was supported by a grant awarded to Dr Perrine Ruby from the French National Agency for research 'Agence Nationale pour la Recherche' (ANR-07-JCJC-0095). The authors declare no conflict of interest.

\section{REFERENCES}

Aserinsky E, Kleitman N (1953). Regularly occurring periods of eye motility, and concomitant phenomena, during sleep. Science 118: 273-274. 
Baars BJ, Ramsoy TZ, Laureys S (2003). Brain, conscious experience and the observing self. Trends Neurosci 26: 671-675.

Benoit O, Foret J (1992). Le sommeil humain: bases expérimentales physiologiques et physiopathologiques. Masson: Paris, 197pp.

Bischof M, Bassetti CL (2004). Total dream loss: a distinct neuropsychological dysfunction after bilateral PCA stroke. Ann Neurol 56: 583-586.

Blagrove M, Pace-Schott EF (2010). Trait and neurobiological correlates of individual differences in dream recall and dream content. Int Rev Neurobiol 92: 155-180.

Bortner RW (1969). A short rating scale as a potential measure of pattern A behavior. J Chronic Dis 22: 87-91.

Bouthillier D, Tremblay N, Hemalin F, Julien D, Scherzer P (1996). Traduction et validation canadienne française d'un questionnaire évaluant l'attachement chez l'adulte. Can J Behav Sci 28: 74-77.

Braun AR, Balkin TJ, Wesensten NJ, Gwadry F, Carson RE, Varga $M$ et al (1998). Dissociated pattern of activity in visual cortices and their projections during human rapid eye movement sleep. Science 279: 91-95.

Braun AR, Balkin TJ, Wesenten NJ, Carson RE, Varga M, Baldwin $\mathrm{P}$ et al (1997). Regional cerebral blood flow throughout the sleep-wake cycle. An $\mathrm{H}_{2}(15) \mathrm{O}$ PET study. Brain 120(Part 7): 1173-1197.

Brown KW, Ryan RM (2003). The benefits of being present: mindfulness and its role in psychological well-being. J Pers Soc Psychol 84: 822-848.

Coez A, Zilbovicius M, Ferrary E, Bouccara D, Mosnier I, AmbertDahan E et al (2009). Processing of voices in deafness rehabilitation by auditory brainstem implant. NeuroImage 47: 1792-1796.

Corbetta M, Patel G, Shulman GL (2008). The reorienting system of the human brain: from environment to theory of mind. Neuron 58: 306-324.

Cory TL, Ormiston DW (1975). Predicting the frequency of dream recall. J Abnorm Psychol 84: 261-266.

Dement W, Kleitman N (1957). The relation of eye movements during sleep to dream activity: an objective method for the study of dreaming. J Exp Psychol 53(5): 339-346.

Dement W, Wolpert EA (1958). The relation of eye movements, body motility, and external stimuli to dream content. $J$ Exp Psychol 55: 543-553.

Domhoff W (2011). The neural substrate for dreaming: is it a subsystem of the default network? Conscious Cogn 20: 1163-1174.

Dresler M, Koch SP, Wehrle R, Spoormaker VI, Holsboer F, Steiger A et al (2011). Dreamed movement elicits activation in the sensorimotor cortex. Curr Biol 21: 1833-1837.

Duvernoy HM (1991). The Human Brain Surface, Three-Dimensional Sectional Anatomy and MRI. Springer: New-York, NY.

Eichenlaub JB, Bertrand O, Morlet D, Ruby P (2013). Brain reactivity differentiates subjects with high and low dream recall frequencies during both sleep and wakefulness. Cereb Cortex; e-pub ahead of print 2 January 2013 (doi:10.1093/cercor/bhs388).

Eichenlaub JB, Ruby P, Morlet D (2012). What is the specificity of the response to the own first-name when presented as a novel in a passive oddball paradigm? An ERP study. Brain Res 1447: $65-78$.

Foulkes WD (1962). Dream reports from different stages of sleep. J Abnorm Soc Psychol 65: 14-25.

Friston KJ, Holmes AP, Worsley KJ, Poline JP, Frith CD, Frackowiak RSJ (1995). Statistical parametric maps in functional imaging: a general linear approach. Hum Brain Mapp 2: 189-210.

Goodenough DR, Shapiro A, Holden M, Steinschriber L (1959). A comparison of 'dreamers' and 'nondreamers': eye movements, electroencephalograms, and the recall of dreams. J Abnorm Soc Psychol 59: 295-302.

Gusnard DA, Raichle ME (2001). Searching for a baseline: functional imaging and the resting human brain. Nat Rev Neurosci 2: 685-694.
Hobson JA (2005). Sleep is of the brain, by the brain and for the brain. Nature 437: 1254-1256.

Hobson JA, Pace-Schott EF, Stickgold R (2000). Dreaming and the brain: toward a cognitive neuroscience of conscious states. Behav Brain Sci 23: 793-842.

Holeckova I, Fischer C, Giard MH, Delpuech C, Morlet D (2006). Brain responses to a subject's own name uttered by a familiar voice. Brain Res 1082: 142-152.

Holeckova I, Fischer C, Morlet D, Delpuech C, Costes N, Mauguiere F (2008). Subject's own name as a novel in a MMN design: a combined ERP and PET study. Brain Res 1189: 152-165.

Johnston DW, Shaper AG (1983). Type A behaviour in British men: reliability and intercorrelation of two measures. J Chronic Dis 36: 203-207.

Jouvet M (1962). Recherches sur les structures nerveuses et les mécanismes responsables des differentes phases du sommeil physiologique. Archives Italiennes de Biologie 100: 125-206.

Knight RT, Scabini D, Woods DL, Clayworth CC (1989). Contributions of temporal-parietal junction to the human auditory P3. Brain Res 502: 109-116.

Kosslyn SM, Ganis G, Thompson WL (2001). Neural foundations of imagery. Nat Rev Neurosci 2: 635-642.

Koulack D, Goodenough DR (1976). Dream recall and dream recall failure: an arousal-retrieval model. Psychol Bull 83: 975-984.

Lavie P (1986). Ultrashort sleep-waking schedule. III. 'Gates' and 'forbidden zones' for sleep. Electroencephalogr Clin Neurophysiol 63: 414-425.

Legrand D, Ruby P (2009). What is self-specific? Theoretical investigation and critical review of neuroimaging results. Psychol Rev 116: 252-282.

Lewis HB, Goodenough DR, Shapiro A, Sleser I (1966). Individual differences in dream recall. J Abnorm Psychol 71: 52-59.

Malaspina D, Harkavy-Friedman J, Corcoran C, Mujica-Parodi L, Printz D, Gorman JM et al (2004). Resting neural activity distinguishes subgroups of schizophrenia patients. Biol Psychiatry 56: 931-937.

Maquet P, Laureys S, Peigneux P, Fuchs S, Petiau C, Phillips C et al (2000). Experience-dependent changes in cerebral activation during human REM sleep. Nat Neurosci 3: 831-836.

Maquet P, Peters J, Aerts J, Delfiore G, Degueldre C, Luxen A et al (1996). Functional neuroanatomy of human rapid-eye-movement sleep and dreaming. Nature 383: 163-166.

Maquet P, Ruby P (2004). Psychology: insight and the sleep committee. Nature 427: 304-305.

Maquet P, Ruby P, Maudoux A, Albouy G, Sterpenich V, Dang-Vu T et al (2005). Human cognition during REM sleep and the activity profile within frontal and parietal cortices: a reappraisal of functional neuroimaging data. Prog Brain Res 150: 219-227.

Marzano C, Ferrara M, Mauro F, Moroni F, Gorgoni M, Tempesta D et al (2011). Recalling and forgetting dreams: theta and alpha oscillations during sleep predict subsequent dream recall. J Neurosci 31: 6674-6683.

Mason MF, Norton MI, Van Horn JD, Wegner DM, Grafton ST, Macrae CN (2007). Wandering minds: the default network and stimulus-independent thought. Science 315: 393-395.

Mazza S, Soucy JP, Gravel P, Michaud M, Postuma R, MassicotteMarquez J et al (2006). Assessing whole brain perfusion changes in patients with REM sleep behavior disorder. Neurology 67: 1618-1622.

McCarley RW, Hobson JA (1975). Neuronal excitability modulation over the sleep cycle: A structural and mathematical model. Science 189: 58-60.

Murri L, Massetani R, Siciliano G, Giovanditti L, Arena R (1985). Dream recall after sleep interruption in brain-injured patients. Sleep 8: 356-362.

Nielsen TA (2000). A review of mentation in REM and NREM sleep: 'covert' REM sleep as a possible reconciliation of two 
opposing models. Behav Brain Sci 23: 851-866 discussion 9041121.

Nir Y, Tononi G (2010). Dreaming and the brain: from phenomenology to neurophysiology. Trends Cogn Sci 14: 88-100.

Opitz B, Mecklinger A, Friederici AD, von Cramon DY (1999). The functional neuroanatomy of novelty processing: integrating ERP and fMRI results. Cereb Cortex 9: 379-391.

Peigneux P, Van der Linden M, Garraux G, Laureys S, Degueldre C, Aerts J et al (2004). Imaging a cognitive model of apraxia: the neural substrate of gesture-specific cognitive processes. Hum Brain Mapp 21: 119-142.

Pichot P, Boyer P, Pull CB, Rein W, Simon M, Thibault A (1984a). Le questionnaire QD 2. La forme abrégée QD 2A. Rev Psychol Appl 4: 323-340.

Pichot P, Boyer P, Pull CB, Rein W, Simon M, Thibault A (1984b). Un questionnaire d'auto-évaluation de la symptomatologie dépressive: le QD 2. Construction, structure factorielle, propriétés métrologiques. Rev Psychol Appl 3: 229-250.

Price CJ (2010). The anatomy of language: a review of $100 \mathrm{fMRI}$ studies published in 2009. Ann N Y Acad Sci 1191: 62-88.

Raichle ME, MacLeod AM, Snyder AZ, Powers WJ, Gusnard DA, Shulman GL (2001). A default mode of brain function. Proc Natl Acad Sci USA 98(2): 676-682.

Raichle ME, Martin WR, Herscovitch P, Mintun MA, Markham J (1983). Brain blood flow measured with intravenous $\mathrm{H}_{2}(15) \mathrm{O}$. II. Implementation and validation. J Nucl Med 24: 790-798.

Raichle ME, Mintun MA (2006). Brain work and brain imaging. Annu Rev Neurosci 29: 449-476.

Raymond JE, Shapiro KL, Arnell KM (1992). Temporary suppression of visual processing in an RSVP task: an attentional blink? J Exp Psychol Hum Percept Perform 18(3): 849-860.

Rechtschaffen A, Kales A (1968). A Manual of Standardized Terminology, Techniques, and Scoring Systems for Sleep Stages of Human Subjects. Brain Information/Brain Research Institute UCLA: Los Angeles, CA.

Renner B (2006). Curiosity about people: the development of a social curiosity measure in adults. J Pers Assess 87: 305-316.

Ruby P (2011). Experimental research on dreaming: state of the art and neuropsychoanalytic perspectives. Front Psychol 2: 286.

Ruby P, Blochet C, Eichenlaub JB, Bertrand O, Morlet D, BidetCaulet A (2013). Alpha reactivity to first names differs in subjects with high and low dream recall frequency. Front Psychol 4: 419.

Ruby P, Decety J (2001). Effect of subjective perspective taking during simulation of action: a PET investigation of agency. Nat Neurosci 4: 546-550.
Ruby P, Decety J (2003). What you believe versus what you think they believe: a neuroimaging study of conceptual perspectivetaking. Eur J Neurosci 17: 2475-2480.

Ruby P, Decety J (2004). How would you feel versus how do you think she would feel? A neuroimaging study of perspectivetaking with social emotions. J Cogn Neurosci 16: 988-999.

Sastre JP, Jouvet M (1979). [Oneiric behavior in cats]. Physiol Behav 22: 979-989.

Schredl M (2002). Questionnaire and diaries as research instruments in dream research: Methodological issues. Dreaming 12: $17-25$.

Schredl M (2004). Reliability and stability of a dream recall frequency scale. Percept Mot Skills 98(Part 2): 1422-1426.

Schredl M, Wittmann L, Ciric P, Gotz S (2003). Factors of home dream recall: a structural equation model. J Sleep Res 12: 133-141.

Shulman GL, Pope DL, Astafiev SV, McAvoy MP, Snyder AZ, Corbetta M (2010). Right hemisphere dominance during spatial selective attention and target detection occurs outside the dorsal frontoparietal network. J Neurosci 30: 3640-3651.

Silber MH, Ancoli-Israel S, Bonnet MH, Chokroverty S, GriggDamberger MM, Hirshkowitz $M$ et al (2007). The visual scoring of sleep in adults. J Clin Sleep Med 3: 121-131.

Silva S, Alacoque X, Fourcade O, Samii K, Marque P, Woods R et al (2010). Wakefulness and loss of awareness: brain and brainstem interaction in the vegetative state. Neurology 74: 313-320.

Simpson JA (1990). Influence of attachment styles on romantic relationships. J Person Soc Psychol 59: 971-980.

Solms M (1997). The Neuropsychology of Dreams: A ClinicoAnatomical Study. Lawrence Erlbaum Associates.

Solms M (2000). Dreaming and REM sleep are controlled by different brain mechanisms. Behav Brain Sci 23: 843-850.

Tochon-Danguy HJ, Clark JC, Janus A, Sachinidis JI (1995). Technical performance and operating procedure of a bedside $\left[{ }^{15} \mathrm{O}\right]$ water infuser. J Labelled Compd Radiopharm 37: 662-666.

Vgontzas AN, Pejovic S, Zoumakis E, Lin HM, Bixler EO, Basta M et al (2007). Daytime napping after a night of sleep loss decreases sleepiness, improves performance, and causes beneficial changes in cortisol and interleukin-6 secretion. $A m J$ Physiol Endocrinol Metab 292: E253-E261.

Wagner AD, Shannon BJ, Kahn I, Buckner RL (2005). Parietal lobe contributions to episodic memory retrieval. Trends Cogn Sci 9: 445-453.

Wamsley EJ, Tucker M, Payne JD, Benavides JA, Stickgold R (2010). Dreaming of a learning task is associated with enhanced sleep-dependent memory consolidation. Curr Biol 20: 850-855.

Witkin HA (1950). Individual differences in ease of perception of embedded figures. J Pers 19: 1-15.

Supplementary Information accompanies the paper on the Neuropsychopharmacology website (http://www.nature.com/npp) 